\title{
Synthesis of organic boron crosslinker for polyvinyl alcohol gel
}

\author{
Zhenhuo Zhang ${ }^{1,2}$, Haijun Liang ${ }^{1,2}$, Xiaolong Wei ${ }^{3}$ \\ 1. National Engineering Laboratory for Low-Permeability Oil \& Gas Field Exploration and Development, Xi'an, Shaanxi, 710018, China; \\ 2. Drilling \& Production Engineering Technology Institute, CNPC Chuanqing Drilling Engineering Company Ltd., Xi'an, Shaanxi, \\ 710018, China; \\ 3. Changqing Downhole Technology Company, CNPC Chuanqing Drilling Engineering Co., Ltd., Xi'an city, Shaanxi 710021, China
}

\begin{abstract}
In this article, borax was used as the prime agent, and the organic boron that cross-linked agent was synthesized using adding sodium tartrate. The synthesis response shapes were optimized using unmarried factor way. The temperature opposition and crosslinking time of the fracturing fluid were used as the appraisal standards to decide the organic boron. The cross-linking agent's optimal synthesis statuses were measured, and the chemical and forcible holdings of the fracturing fluid after cross-linking with the polyvinyl alcoholbased liquid were measured.
\end{abstract}

Keywords: polyvinyl alcohol; fracturing fluid; organic boron; crosslinker.

\section{Introduction}

Fracturing is an significant measure to enhance gas recuperation and petroleum, raise petroleum yield and raise injection of water injection wells[1]. Its derivatives and tannin are the most usually applied thickeners for water-based that fractures operating fluids. They have good temperature resistance and strong viscosityincreasing ability, but it is difficult to break the fracturing fluid[2-4]. Water-insoluble affair and remaining colloidal flecks will the constitution to harm, decrease the proppant's conductivity, and the cost fluctuates greatly. Polyvinyl alcohol takes a definite thickening capability, and can compose a hydrogel using cross-linking response, which not only has traditional polymer's rheology fracturing fluid, masteries fluid cost, but also owns depressed price, convenient gel breaking and small harm to the reservoir. A appropriate crosslinking agent's arrangement is key to its application as a fracturing fluent thickener[5-7]. The organoboron that cross-links agent has the capability to crosslink with a hydroxyl band. Based on the fracturing fluent system of polyvinyl alcohol as a thickening agent, a appropriate organoboron that cross-linked agent was consequently synthesized by using altering the response temperature, response time[8-9].

\section{Experimental}

\subsection{Materials}

Polyvinyl alcohol (2488 flecks) industrial degree, borax, sodium potassium tartrate, sodium hydroxide are analytic degree.

\subsection{Instrument}

$250 \mathrm{ml}$ three-necked flask, booster electrical mixer, electrical incessant temperature water bath, six-speed rotary viscometer (ZNN-D, Qingdao Camera plant), complex rheometer, attractive stirrer, electronic balance, stopwatch.

\subsection{Synthesis of organoboron crosslinker}

Put a magnet in a $250 \mathrm{ml}$ three-necked flask and add water. Put it in a attractive stirrer that is equipped with a condensing reflux instrument. After increasing the temperature to the response temperature, adapt the $\mathrm{pH}$ value, weigh the borax, add a three-necked flask, and stir to all the borax. Fade Away, add the ligand potassium sodium tartrate, and respond for a positive span of time to acquire an organic boron crosslinker.

\section{The synthesis of organic boron is divided into two steps.}

\subsection{Hydrolysis reaction}

$$
\begin{gathered}
\mathrm{Na}_{2} \mathrm{~B}_{4} \mathrm{O}_{7}+7 \mathrm{H}_{2} \mathrm{O} \rightarrow 2 \mathrm{Na}^{+}+4 \mathrm{~B}(\mathrm{OH})_{3}+2 \mathrm{OH}^{-} \\
B(\mathrm{OH})_{3}+\mathrm{H}_{2} \mathrm{O} \Leftrightarrow \mathrm{B}(\mathrm{OH})_{4}^{-}+H^{+}
\end{gathered}
$$




\subsection{Complexation reaction}

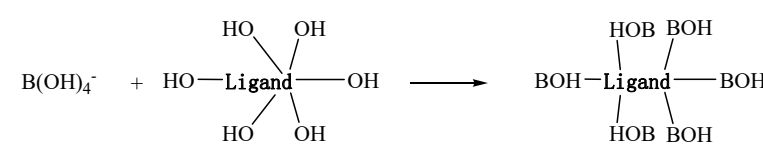

\subsection{Physical and chemical properties evaluation of fracturing fluid}

In thickener determination's instance, cross-linking temperature opposition and time are two significant performance indicators of whether the cross-linking agent is brilliant. The two indicators are used as the appraisal basis, and the Chinese petroleum and gas industry quality SY/T5107-2005 The performance appraisal approach of water-based that fractures fluid is an assessment approach, and the synthesis statuses are optimized.

\subsection{Viscosity performance}

The viscosity at $170 \mathrm{~s}^{-1}$ varying temperature was evaluated by using complex rheometer.

\subsection{Salt resistance}

The evident viscosity of the cross-linked PVA that fractured fluid was assessed by using six velocity rotational viscometer, and the alteration of the evident viscosity at varying temperatures after adding varying salts was researched.

\subsection{Suspended grit performance}

Add $5 \mathrm{~g}, 10 \mathrm{~g}, 15 \mathrm{~g}, 20 \mathrm{~g}, 25 \mathrm{~g}, 30 \mathrm{~g}, 35 \mathrm{~g}, 40 \mathrm{~g}$ of sand to each of the eight beakers that contain polyvinyl alcohol that fractures fluid, stir equally, then pour into the measuring cylinder, and count with a stopwatch while pouring. Record the time demanded for the sand to locate at varying temperatures; use the ruler to evaluate the height of the sand that is taken in the cylinder and figure the sedimentation speed, after the sand sinks.

\section{Results and discussion}

From the literature, the polyvinyl alcohol foundation answer concentration was $2 \%$, and the crosslinking proportion was 100:1. Borax in the shape of boric acid ions in aqueous answer can be rather varying from polyols beneath positive statuses. In this article, a unmarried ligand sodium tartrate is used to synthesize an organoboron that cross-links agent.

\subsection{Effect of reaction temperature on organ boron crosslinking agent}

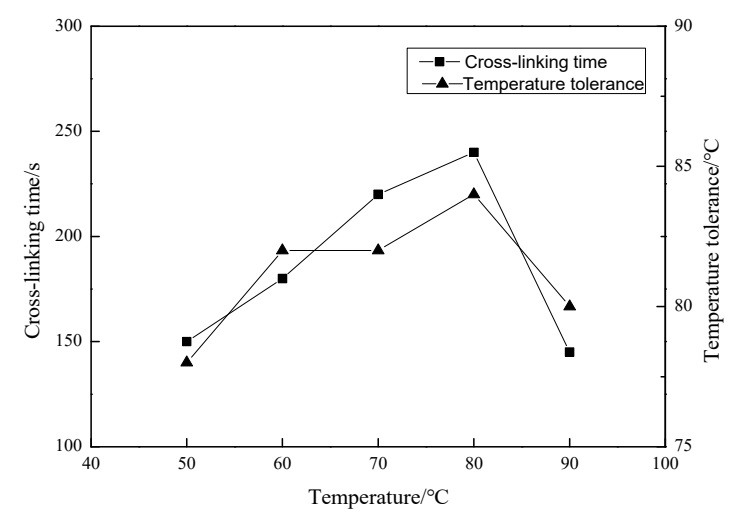

Fig. 1 Effect of reaction temperature on organoboron crosslinking agent

It can be seen from statue 1 that while the response temperature is depressed, organoboron's complexation is not complete, the borate ion is not entirely reacted, the crosslinking time is poor, and the temperature defiance is short. The temperature opposition and crosslinking time step by step grow and arrive in the optimal at 80 extents Celsius, as the response temperature builds up. If the temperature is excessively eminent, the chain connections will be split and the temperature defiance will be deteriorated, so the response temperature is picked to be $80^{\circ} \mathrm{C}$

\subsection{Effect of borax addition}

Until experimental preliminary research and literature study, the set response statuses were $1.5 \% \mathrm{NaOH}, 20 \%$ ligand, $4 \mathrm{~h}$ response time and $80^{\circ} \mathrm{Creaction}$ temperature. The quantity of borax was modified to research the synthesized organic boron crosslinker. The temperature resistance's influence and crosslinking the gel's time with polyvinyl alcohol was noticed. The experimental consequences are as follows:

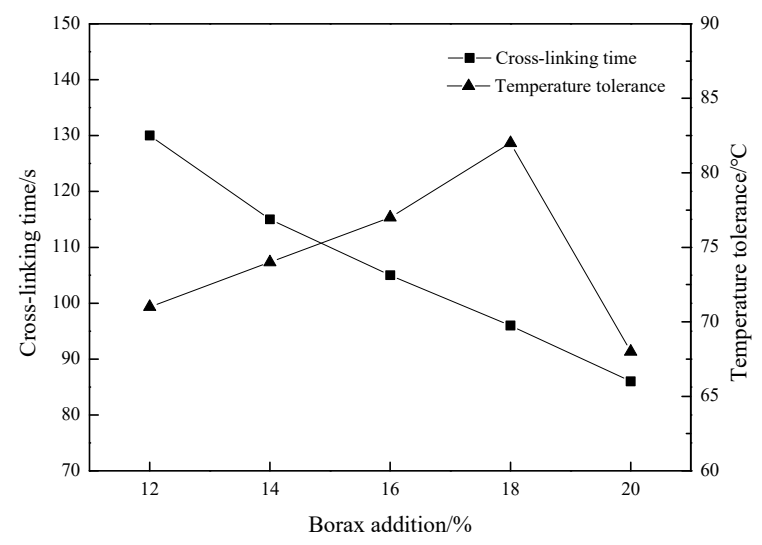

Fig. 2 Effect of borax addition on the performance of organoboron crosslinkers

Fig. 2 shows that as the amount of borax rises, the crosslinking time decreases, and the temperature resistance first rises and then decreases. While the 
quantity of borax is minor, the interaction degree with the ligand is less, the ligand encapsulates a bit of boron, and lento discharges, prolonging the crosslinking time, but cross-linking with polyvinyl alcohol to compose the fracturing smooth jelly's temperature defiance. Inadequate. Suppose the quantity of borax is inordinate, the unreacted borate responds with the cis- ortho-hydroxy band of the polyvinyl alcohol, the crosslinking time goes brief, and yet the phenomenon of "over-crosslinking" exists, and the temperature defiance is deteriorated. While the quantity of borax is $18 \%$, the temperature defiance is excellent, getting $82^{\circ} \mathrm{C}$.

\subsection{Effect of Ligand on Organic Boron Crosslinking Agent}

Other experimental statuses were unchanged, the quantity of ligand was merely varied, and the impact of crosslinking with polyvinyl alcohol on the temperature defiance of the crosslinking time and the fracturing fluid was researched.

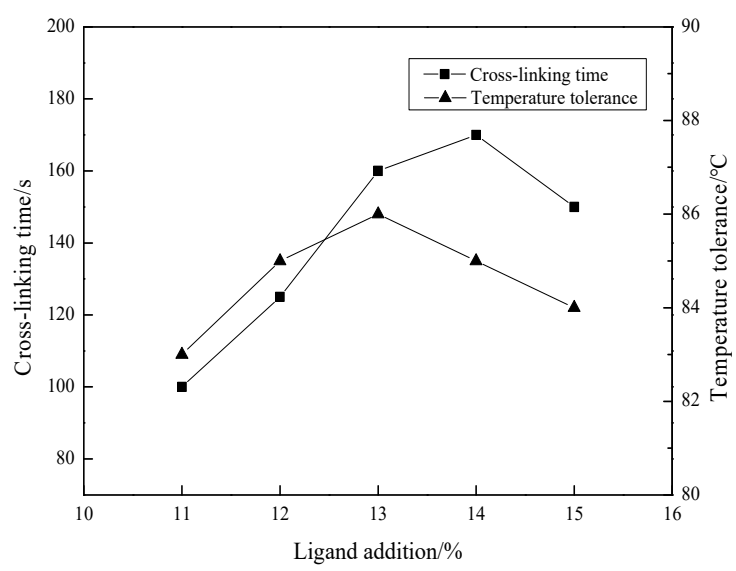

Fig. 3 Effect of ligand addition on the performance of organoboron crosslinkers

As the quantity of ligand growths, the crosslinking time growths, and the temperature opposition first builds up and then goes down. While the quantity of the ligand is minor, the crosslinking time is brief and the temperature opposition is not excellent. The addition quantity of the ligand grows, and the surplus ligand is wrapped outside the organic boron, which takes a shielding consequence on the complexation of the polyvinyl alcohol and the crosslinking agent. The consequence of the ligand addition sum of $13 \%$ is soundest in the above statue.

\subsection{Effect of reaction time on organoboron crosslinking agent}

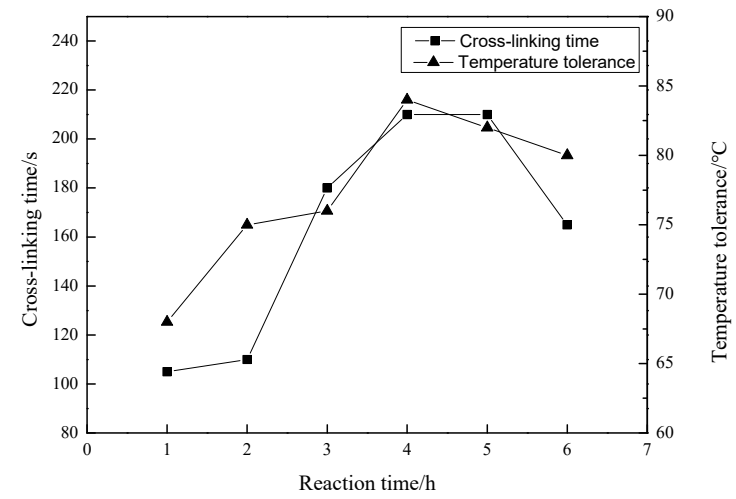

Fig. 4 Effect of reaction time on the performance of organoboron crosslinkers

While the response time is brief, the borate response in the crosslinking agent is not complete, the temperature defiance is not excellent, and the crosslinking time is poor. With the growth of response time, the temperature defiance and crosslinking time are bit by bit augmented. While the response time gets into $4-5 \mathrm{~h}$, the crosslinking time and temperature defiance are optimum.

\subsection{Effect of $\mathrm{NaOH}$ Addition on Organic Boron Crosslinking Agent}

To to upgrade borax's hydrolysis response, more borate ions are built in the answer, and the complexation response is speeded up. $\mathrm{NaOH}$ is overall added as a accelerator, and the accelerator has got small impact on the temperature defiance and crosslinking time. In this experimentation, the consequence of the stability of the organoboron that cross-linked agent was enquired into by using adapting the quantity of $\mathrm{NaOH}$ and other statuses.

Table 1. Effect of $\mathrm{NaOH}$ addition on the stability of crosslinker

\begin{tabular}{cc}
\hline $\mathrm{NaOH}$ addition $/ \%$ & stability \\
\hline 0 & stable \\
0.5 & stable \\
1.0 & a small amount of precipitation \\
1.5 & There is a lot of precipitation \\
2.0 & There is a lot of precipitation \\
\hline
\end{tabular}

With the increase of $\mathrm{NaOH}$, the same time can be placed at room temperature, and the synthesized organic boron cross-linking agent will gradually precipitate out crystals. It is suitable to select $1.0 \%$ of $\mathrm{NaOH}$. 


\subsection{Viscosity performance}

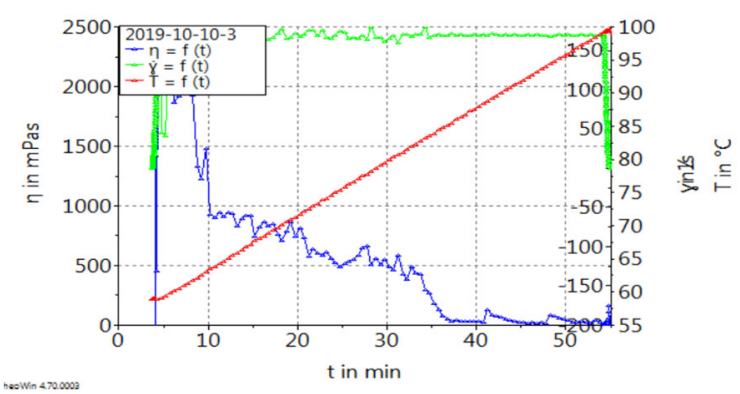

Fig. 5 Viscosity curve of polyvinyl alcohol fracturing fluid

With the complexity of fracturing, the depth of gas wells and oil is growing, so that the temperature opposition of fracturing fluids is greatly checked, and fracturing fluids with excellent thermal stability are demanded. As is visible from the above statue, the fracturing fluid's viscosity as a whole indicates a downward tendency, as the system's temperature goes up. Ahead of the temperature is up to $80^{\circ} \mathrm{C}$, the viscosity declines considerably, after which the viscosity is yet falling, but the rate is reduced. While the system's temperature is lifted to $83^{\circ} \mathrm{C}$, the viscosity is $53.3 \mathrm{mPa} \bullet \mathrm{s}$, which runs into the criteria of seam making and sand carrying, showing that the fracturing fluid takes more beneficial temperature opposition.

\subsection{Salt resistance}

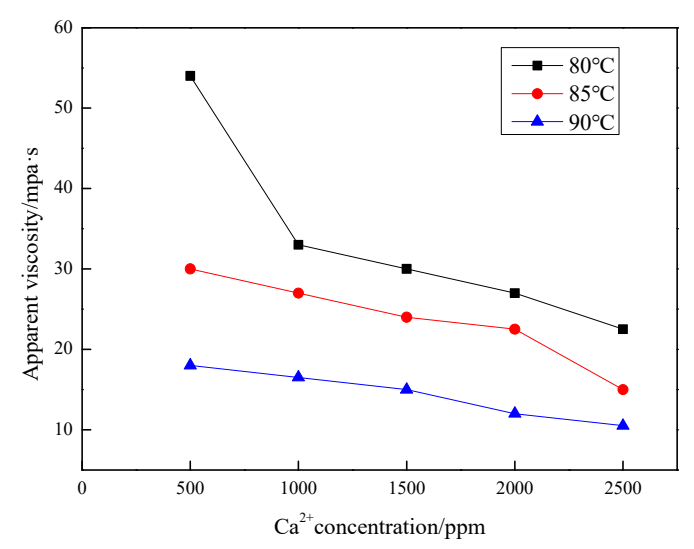

Fig. 6 Calcium resistance of polyvinyl alcohol fracturing fluid at different temperatures

According to Fig. 6, while the concentration of $\mathrm{Ca}^{2+}$ in the fracturing fluid at $80^{\circ} \mathrm{C}$ is $500-1000 \mathrm{ppm}$, the fracturing fluid's evident viscosity goes down speedily. While the concentration of $\mathrm{Ca}^{2+}$ is $1000-2500 \mathrm{ppm}$, the obvious viscosity of the fracturing fluid at $85^{\circ} \mathrm{C}$ falls down lento. While the concentration of $\mathrm{Ca}^{2+}$ in the fracturing fluid at $90^{\circ} \mathrm{C}$ is $500-1000 \mathrm{ppm}$, the fracturing fluid's patent viscosity goes down lento with small alteration. It can be viewed that the stress fluid at $85^{\circ} \mathrm{C}$ and $90^{\circ} \mathrm{C}$ the fracturing fluid has got good salt defiance.

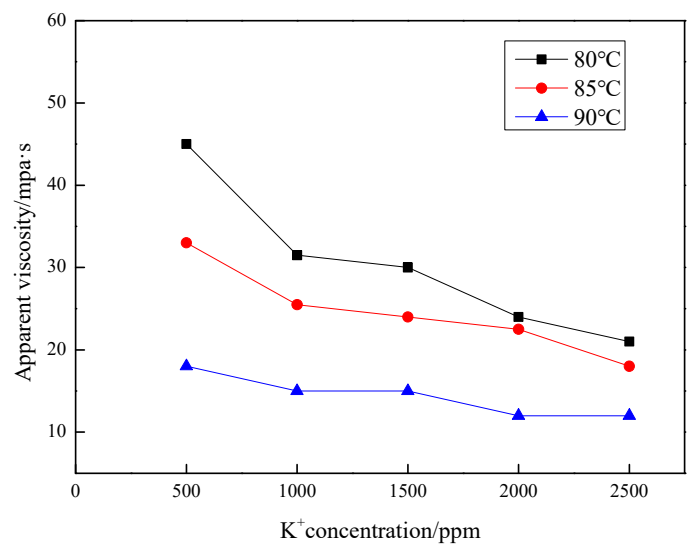

Fig. 7 potash resistance of polyvinyl alcohol fracturing fluid at different temperatures

from statue 7 that while the $\mathrm{K}^{+}$concentration of the fracturing fluid at $80^{\circ} \mathrm{C}$ is $500-1000 \mathrm{ppm}$, the evident viscosity falls down speedily; while the $\mathrm{K}^{+}$concentration is $1000-1500 \mathrm{ppm}$, the apparent viscosity virtually stays unchanged; when the $\mathrm{K}^{+}$concentration is $1500-2500 \mathrm{ppm}$, the evident viscosity falls down speedily; while the $\mathrm{K}^{+}$ concentration of the fracturing fluid at $85^{\circ} \mathrm{C}$ is 500 $1000 \mathrm{ppm}$, the evident viscosity goes down speedily; while the $\mathrm{K}^{+}$concentration is $1000-2500 \mathrm{ppm}$, the obvious viscosity falls down lento; while the $\mathrm{K}^{+}$concentration of the fracturing fluid at $90^{\circ} \mathrm{C}$, the patent viscosity goes down speedily. The evident viscosity alters little at $500 \sim$ $2500 \mathrm{ppm}$, showing that the fracturing fluid at $90^{\circ} \mathrm{C}$ has got more excellent salty opposition.

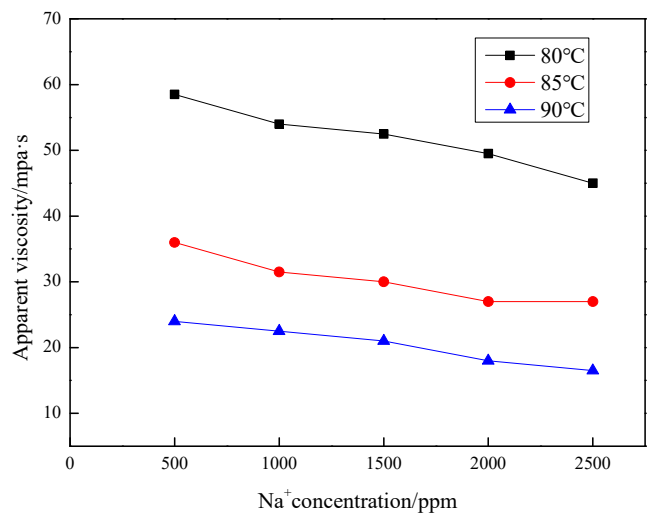

Fig. 8 salt resistance of polyvinyl alcohol fracturing fluid at different temperatures

According to Fig. 8, the $\mathrm{Na}^{+}$concentration of fracturing fluid at $80^{\circ} \mathrm{C}$ goes down step by step at 500-2500ppm, and the obvious viscosity goes down lento at $90^{\circ} \mathrm{C}$ and $85^{\circ} \mathrm{C}$ at $500-2500 \mathrm{ppm}$. It can be viewed that the fracturing fluid at $90^{\circ} \mathrm{C}$ and $85^{\circ} \mathrm{C}$ has got more excellent salty opposition. 


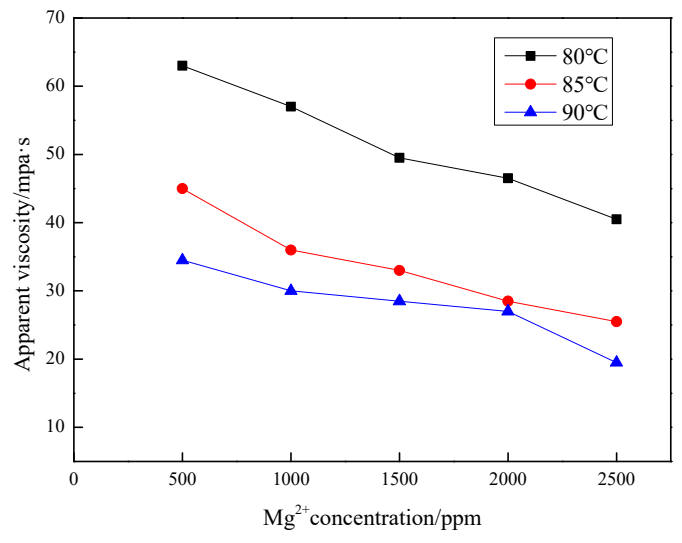

Fig. 9 Magnesium salt resistance of polyvinyl alcohol fracturing fluid at different temperatures

According to Fig. 9, the $\mathrm{Mg}^{2+}$ concentration of the fracturing fluid at $80^{\circ} \mathrm{C}$ step by step diminishes from 500 to $2500 \mathrm{ppm}$, and the obvious viscosity declines quickly while the concentration of $\mathrm{Mg}^{2+}$ in the fracturing fluid at $85^{\circ} \mathrm{C}$ is from 500 to $1000 \mathrm{ppm}$, and reduces from 1000 to $2500 \mathrm{ppm}$. The obvious viscosity of the fracturing fluent $\mathrm{Mg}^{2+}$ concentration at $90^{\circ} \mathrm{C}$ is not lento a lot modified at 500 2000ppm, and it diminishes speedily at 2000 2500ppm. It can be watched that the fracturing fluid at $90^{\circ} \mathrm{C}$ possesses more excellent salty opposition.

\section{Conclusion}

(1) The cross-linking agent's optimal synthesis statuses are as follows: response temperature $80^{\circ} \mathrm{C}$, borax addition sum is $18 \%$, ligand addition sum is $13 \%$, response time is 4-5 $\mathrm{h}$, and $\mathrm{NAOH}$ addition sum is $1 \%$;

(2) The polyvinyl bromide that cross-links agent that is synthesized beneath the polyvinyl alcohol-based limpid cross-linked polyvinyl alcohol fracturing fluid and the optimum synthesis statuses take excellent temperature and shear defiance : the fracturing fluid is at a shear rate of $170 \mathrm{~s}-1$ while the system is heated to $83^{\circ} \mathrm{C}$, its viscosity is $53.3 \mathrm{mPa} \cdot \mathrm{s}$;

(3) The cross-linking time of the polyvinyl alcohol that fractures fluid after crosslinking of the organoboron that cross-links agent that is synthesized beneath the superlative synthesis statuses with the polyvinyl alcoholbased liquid is $220 \mathrm{~s}$.

\section{Acknowledgments}

The work was supported financially by Shaanxi Provincial Key Research and Development Program (2019GY-136), Key Scientific Research Program of Shaanxi Provincial Department of Education (21JY035) and Youth Innovation Team of Shaanxi University. And we thank the work of Modern Analysis and Testing Center of Xi'an Shiyou University.

\section{References}

1. Yongwei SONG, Heru WANG. Using polyvinyl alcohol to improve the deacidification performance of titanium white waste acid: Pilot tests[J]. Waste Management, 2019, 87, p. 13-20

2. Xiaosen SHANG, Yunhong DING, Yonghui WANG. Rheological and Performance Research on a Regenerable Polyvinyl Alcohol Fracturing Fluid. [J]. PloS one, 2015, 10(12), P. 44-49

3. Siming YAN, Yongji WANG, Jia HE. Performance of the reproducible polyvinyl alcohol fracturing fluid system. [J]. Russian Journal of Applied Chemistry, 2015, Vol. 88 (11), p. 1884-1891

4. Yanping HOU, Kaiming LI, Haiping LUO. Using crosslinked polyvinyl alcohol polymer membrane as a separator in the microbial fuel cell[J]. Frontiers of Environmental Science \& Engineering, 2014, 8(1), p. 137-143

5. Kyunghwan Yoon, Benjamin S. Hsiao, Benjamin Chu.High flux ultrafiltration nanofibrous membranes based on polyacrylonitrile electrospun scaffolds and crosslinked polyvinyl alcohol coating[J]. Journal of Membrane Science, 2009, 338(1-2), p. 145-152

6. Ashveen V. Nand, David R. Rohindra, Jagjit R. Khurma. Characterization of Genipin Crosslinked Hydrogels Composed of Chitosan and Partially Hydrolyzed Poly(vinyl alcohol)[J]. Polymers, 2013, 7(1), p. 402-410

7. Ruiyun Zhang, Wenyu Xu, Fuqing Jiang. Fabrication and characterization of dense Chitosan/polyvinylalcohol/poly-lactic-acid blend membranes[J]. Fibers and Polymers, 2012, 13(5), p. 571-575

8. Chang Suk Kong, Wan Suk Yoo, Kui Young Lee. Nanofiber deposition by electroblowing of PVA (polyvinyl alcohol)[J]. Journal of Materials Science, 2009, 44(4), p. 1107-1112

9. Shefali Mishra, R. Bajpai, R. Katare. On the mechanical strength of biocompatible semi-IPNs of polyvinyl alcohol and polyacrylamide[J]. Microsystem Technologies, 2008, 14(2), p. 193-198 